\title{
Personal Variables as Correlate of Drug Use Behaviour among Secondary School Students in Osun State, Nigeria
}

\author{
Alimi, Kuburat Mojirade. Ph. D \\ o/cDepartment of Educational Foundations and Counselling, Obafemi Awolowo University. Ile-Ife \\ Email: alimikudirat@yahoo.com \\ Olayiwola, Idowu Olusola. Ph. D. \\ o/cDepartment of Educational Foundations and Counselling, Obafemi Awolowo University. Ile-Ife \\ Email: olayiwolasola2006@yahoo.com
}

\section{Doi:10.5901/jesr.2015.v5n2p205}

\begin{abstract}
This study examined the influence of personal variables (age, sex, academic-class and religion) on drug use behaviour among secondary school students in Osun State. Nigeria. Descriptive research design was employed. The sample for this study was 1800 students selected randomly from thirty secondary schools randomly selected from six Local Government areas of Osun state. The Local Government areas were: Ife North, Iwo, Orolu, Ife-South, Odo-otin and Atakumosa. Drug Use Behaviour Inventory (DUBI), Drug Use Behaviour Assessment Interview Schedule (DUBAIS) and Life Orientation Test-Revised (LOT-R) were the three instruments used to elicit information from the respondents. Data were subjected to Relative Significant Index, descriptive and Chi-square Statistics Findings indicated that there was no significant relationship between drug use behaviour, sex and religion, but drug use behaviour was significantly influenced by age and academic class. The study concluded that an understanding of predictors of drug use behaviour is necessary among secondary school students. Recommendations were made and necessary conclusion drawn.
\end{abstract}

Keywords: Personal variables, drug use, correlate, life orientation

\section{Introduction}

The alarming evidence in the prevalence of drug abuse, the effects and consequences of substance abuse among students has called for concern and challenge to all helping professions to mount strategies of equipping youths with skills of living devoid of substance abuse. In Nigeria today, the consequences of substance use are diverse, including acute and chronic health, social as well as psychological problems. There is disruption of interpersonal relationships particularly within the family, marginalization, criminal behaviour, school failure, vocational problems and failure to achieve normal adolescent developmental tasks, yet these adolescents are expected to be the leaders of the country in the future when they do not even have any focus for the future. Several studies carried out among the secondary school students on drug abuse by Omage and Oshiloya, (2006), Nwagwu, (1999), Fayombo and Aremu (2000) and Obianwu, (2005) found that students and youths are involved in cannabis abuse and stimulants such as amphetamines and cannabis. The consensus of opinion therefore seems to be that youths are also seriously involved in substance abuse. Drug abuse has become such a problem of great concern to all well meaning Nigerians and particularly the Federal Government to the extent that an Agency has been established to combat the social disease with a view to reducing the spread of drug abuse to the barest minimum or eradicating it totally.

Research studies indicated that drug taking is not peculiar to a set of students of a particular age, sex academicclass religion. Studies conducted on drug use behaviour revealed that majority of drug abuse started by using tobacco while in their teenage years. In particular, Ethen (2000) reported the cases of children who were 12 years old and who were smokers. In the same vein, Shobola (2004) reported that smoking is a common phenomenon among university students irrespective of their age, sex, religious beliefs and academic discipline.

The changing patterns in age and sex of drug abusers indicated that drug abuser starts at an early age and sex variation depends on substance of abuse (Flisher, Parry, Evans, Muller, Lobard, 2003). Religion shapes young people's attitudes. All religions have certain feelings towards what is acceptable to put into human bodies as means of intoxication 
for spiritual, pleasure or medicinal purposes. Investigating into young people's behaviour concerning drug use behaviour could reveal the influence of personal variables on drug use behaviour. Researchers have found that youths who abuse drugs are exposed to them early in life from many sources such as parents, peer groups and mass media (Obot, 2000; and Odejide, 2000). In many African societies as is done elsewhere in the world alcohol is commonly used at social ceremonies such as marriages, naming, meetings, wake keep and chieftaincy occasions. The consumption of alcohol and other drugs at such occasions becomes an accepted norm. It is not criticized at such times even in the presence of parents and elders in the societies. This could be a temptation for youths to avail themselves to its consumption.

Adolescents use drugs in imitation of their peer group and friends. They take drugs with the intent to belong to a peer group in an attempt to avoid being odd in the group or being thrown out of the group. Innocent youths may show willingness to indulge in drug abuse. The drugs identified as being used by different population subgroups but mostly the youths in Nigeria include alcohol and alcoholic beverages such as local brews, palm wine, local gin known as "Ogogoro" or "Apetesi" and imported spirits (wine, brandy, whisky). Others being commonly used are indian hemp, tranquilizer and psycho-stimulants (International Council on Alcohol and Addiction, 1988). Madubuike (2002) and Odejide (2000) confirmed that Nigerian youths are typified in the literature as people who use and abuse licit and illicit drugs.

Statement of the Problem

Drug abuse is a major public health problem all over the world United Nations Organisation on Drug Council (UNODC, 2005). Nigerian schools, for instance, are characterized with drug abuse among students, giving rise to diverse anti-social ills such as rape, mass failure in examinations, indiscriminate sexual acts, unintended pregnancies, low self-concept, truancy, lying and stealing and many other vices that may interfere with teaching/learning and peaceful atmosphere in the school settings. Students who abuse drugs are seen as threats to the peace and security of their institutions.

Majority of secondary school students are in the adolescent stage of life. They are very curious and likely to experiment with drugs. Apart from the effects of drug abuse on academic work, it is associated with multifarious problems, which are evident in social, psychological, health and economic levels of functioning of individuals and the society at large. Osikoya and Alli (2006) asserted that socially, a drug abuser is always preoccupied with how to obtain drug of choice and crave for the substance. Attention is diverted from learning and other schools activities as he or she is absent from school frequently. Majority of drug abusers have no respect for constituted authorities and criminal behaviours are often associated with drug abuse. Condemnable activities such as armed robbery and kidnapping are perpetuated mostly when people are under the influence of drug abuse. Psychologically, the effects of most drugs abused include symptoms of stress, anxiety, depression, behaviour changes, fatigue and loss or increase in appetite. Obot (2000) and Odejide (2000) warned that drug abusers who exhibit these symptoms should be treated to save them from deadly diseases because their neglect may lead to loss of future manpower for the country (Nigeria).

In the light of this, the following questions may be raised:

- Do personal variables (age, sex, academic class and religion) influence drug use behaviours?

- To answer this research question an hypothesis was generated which read thus: personal variables (Age, sex ,religion and academic-class ) has no significant relationship with drug use behaviour

With the issue raised above, there is the need to determine the influence of personal variables on drug use behaviour among secondary school students with a view to reducing the risk factors associated with drug use behaviour

\section{Literature Review}

\subsection{Age}

The use of drugs among youths almost always increases with age. With no exception, initiation at the use of each drug occurred in early adolescent life in our youths. Reports have shown that initiation at use of most drugs start quite early in adolescents (Eneh and Stanley, 2004). Onigbodun and Babalola (2004) reported that there was a tendency to abuse the more illicit drugs in the late adolescent period. They explain further that adolescents that abuse substances become increasingly involved as they get older. Cynthia, Lawrence, Mark and Jocelyn (2008) noted that the oldest adolescents in their studies were more likely to test positive for drug use than younger adolescents.

In a descriptive epidemiological survey of substance use and disorders in Nigeria during the early century, Gureje, Degenhart, Benjamin, Richard, Owoidoho, Abba, Olusola, Olley, Kupling and James (2007) explained that there appeared to be no age differences for past years use of alcohol and tobacco, with the exception of higher rates of tobacco use among middle aged adults compared to young adults. 
Many previous studies on drug abuse in Nigeria and elsewhere in Africa (Abiodun, Adelekan, Ogunremi, Oni, \& Obayan 1994; Odejide 2000; Flisher, Parry, Evans, \& Lombard, 2003) found that drug abusers commonly starts in adolescent and young adulthood. They found that about half of life time users had commenced use by the age of 20 years for alcohol, cannabis and tobacco and 25years for non-prescription use of sedatives and stimulants. Alcohol tends to gain early prominence followed by tobacco and then cannabis as reported (Gureje et al, 2007).

Age-related differences in parent and peer influence was recorded in cross sectional or longitudinal studies of adolescent smoking habit. Adolescents are increasingly dominated by their peers, at least in terms of cigarette smoking as specific problem behaviour. From the longitudinal data picture of adolescence as age periods when both parents and peer influences on cigarette smoking were noted. In addition, there were some evidences of a decrease in parental influence (Fisher \& Pary, 2003). Age differences were observed on several functions of drugs, abusers who had used a drug to feel elated or euphoric or help to sleep tended to be older and those who used drugs to stop worrying about a problem were younger (Annabel, John and John, 2001). They maintained that if future studies confirm these differences, education Programme and interventions might benefit from tailoring their strategies for specific age groups and sexes.

Sex: The reports on gender differences in drug abuse have not been consistent among various studies (Abiodun, Adelekan, Ogunremi, Oni and Obayan, 1994; Anochie, Nkanginieme, Eke and Alukor, 1999; Fatoye and Morakinyo, 2002). They reported that males used alcohol, kolanut and coffee more often than the females. The use of cigarette and cannabis was the exclusive preserve of the males. Use of these substances is still regarded as a male habit in the environments of their studies. The females abused the inhalants and the tranquillizers more than the males. Variation in gender difference would also have been influenced by the environment. Highly industrialized cities such as Port-Harcourt would likely have more females abusing substances compared with cities such as Enugu and Ilorin.

Epidemiological data from school surveys in Nigeria show a rise in consumption, as well as early initiation, increasing female involvement, and a trend towards multiple substance use and abuse among adolescents in Nigeria (Adelekan, Makanjuola, Ndom 2001; Onigbodun and Babalola, 2004). Similarly, Oye et al (2001) reported that sex differences existed across past years for alcohol and tobacco use, but no difference existed for non-prescription sedative use.

Several gender differences were observed in the combined functions of recent drug use. Researchers indicate that young females use other drugs as well as cocaine as social supports. Using for specific physical effects (weight loss, sex or wakefulness) was also more common among young women. In contrast, male users were significantly more likely to report using at least one of the target substances to try to improve the effects of another substance. This indicates a greater tendency for young males in this study to mix drugs than their female counterparts (Annabel, John \& John, 2001).

Sex differences were observed in the effects of peers and parent influences on subsequent behaviours. When sex differences were found, the pattern of these differences showed that peer and parent influences were significant to girls but not for boys. These findings are consistent with previous research in substance use is suggesting that girls are more susceptible to outside social influences than are boys.

In a study conducted on substance use among secondary school setting in an urban setting in Nigeria. Oshodi, Aina, \& Onajole, (2010) maintained that for most of the substances abused, there were more male users than females, but the gender differences were small and statistically non-significant. This apparent gender bias in the use of substances is in line with findings from previous studies (Fatoye and Morakinyo, 2002; Abdulkarim, Mokuolu and Adeniyi; 2005; Makanjuola, Daramola \& Obembe, 2007).

Ensminger (1982) noted that shyness and aggressiveness may be less important predictors of substance use among females than among males because girls peer groups are smaller and less important to them. Ensminger (1990) reported that children who are ready for school are those who experiment with drugs most. Significant family relationships are also important to girls than to boys in terms of influencing psychiatric symptoms. Mothers had an important effect on the psychological status of their daughters but not of their sons. Mothers' expectations of how far daughters would go in school and mothers own psychological health were positive factors in their daughter psychological well being in later years. Ensminger, Brown and Kellam (1982) found that girls with strong family bonds tend to use drug less than other girls do, but the same family influence is not so apparent with boys.

Both men and women use drugs but addiction research has focused largely on males. In the earliest ethnographic studies of heroin misuse conducted in U.S (Finestone, 1957; Sutter, 1966, 1969, 1972; Feldman, 1968 and Preble and Casey, 1969) street addicts were portrayed as innovative, self -determining men who somehow managed to carve out an active role for themselves in an otherwise hostile world. This image was maintained in later research where male drug users were similarly described as busy, self-respecting individuals who actively confronted and purposely responded to external constraints and life opportunities (Waldorf, 1973; Agar, 1979; Biernacki, 1979; Hanson, Beschner, Walters and 
Bovelle, 1985; Johnson, Goldstein, Preble Schneider, Lipton, Spunt and Miller, 1985; Bourgosi, 1996). By contrast, female drug users have often been portrayed as victims or as weak, self - destructive and insecure individuals who were sicker, more deviant and more psychologically disturbed than their male peers (Rosenbaum, 1981; Ettorre, 1992; 1994; Taylor, 1993\& Pettiway, 1997).

Recently, female drug abuse has tended to be examined in relation to narrow range of women's issues such as the effects of addiction on child birth, child rearing and parenting (Murphy and Rosenbaum, 1995) and involvement of women drug users in prostitution (Perkins and Bennet, 1985; Freund, Leonard and Lee, 1989;). Researchers have shown that females report shorter progression from first drug abuse to dependence than men (Anglin and McGlothin, 1987; Mc-Cance-katz ,Carroll and Rounseville, 1999) , are more likely to share used injecting equipment and to have a sexual partner who is also a drug user (Barnard, 1993; Becker and Duffy, 2002). Disproportionate numbers of drug dependent females have suffered post-traumatic experiences such as sexual abuse, incest, domestic violence or death of a child or a still birth (Horgan, Cassidy and Corrigan, 1998; El-Bassel, Gilbert, Schilling and Wada, 2000; Gilbert, ELBassel, Rajah, Feleno and Frye, 2001; Becker and Duffy, 2002). Likewise, female drug users experience particularly high levels of mental health problems including low self-esteem, depression, anxiety and suicidal feelings (Gilbert et al., 2001; Becker \& Duffy, 2002).

\subsection{Religion}

All religions have certain feelings towards what is acceptable to put into human bodies as a means of intoxication, for spiritual, pleasure or medicinal purposes.

Religions membership has been included in many research studies than almost other variables and has a highly consistent ability to predict the non-drug uses (Gorsuch and Butter, 1976) for Christianity and Islam. However, there are some African traditional religions like Obatala, Ogun and Egungun that encourage the use of local alcohols like palmwine and Burukutu. In a descriptive epidemiology of substance use and disorders in Nigeria during the early century, Gureje, Degenhart, Olley, Uwakwe, Udofia, Olusola, Kipling and James (2007) reported that differences in drug use were observed according to religious affiliation of the participants surveyed. Moslems were less than Christians (Catholics and Protestants) who have used alcohol or sedatives in the past years, and more likely than the latter two groups to have used tobacco. Similarly study conducted on substance use among South Africa University students indicated that cannabis is used during religious ceremonies most especially for Holy Communion and also used during other rituals (Karl \& Nancy, 1999).

\subsection{Research Method}

The study was a descriptive research design as it sought to study the incidence of drug use behaviour among secondary school students in Osun state. The design also enabled the researcher to describe the influence of personal variables on drug use behaviour of the subjects. The sample for this study was 1800 students selected from thirty secondary schools randomly selected from six Local Government areas of Osun state. The Local Government areas were: Ife North, Iwo, Orolu, Ife-South, Odo-otin and Atakumosa. A multistage sampling technique was employed to select the study sample. Six Local Government areas were randomly selected from the 30 LGAs in the state after which two junior and three Senior Secondary Schools were randomly selected across three academic class levels. The students were stratified into sex (Male and female) and school location (Urban and Rural). In all, 900 males and 900 females participated in the study.

The characteristics of the respondents are presented in Table 1.

Table 1: Demographic Characteristics of Respondents

\begin{tabular}{|c|c|c|c|c|}
\hline Variables & & Male & Female & Total \\
\hline \multirow{4}{*}{ Class } & JSS 1 & 120 & 120 & 240 \\
& JSS 2 & 120 & 120 & 240 \\
& JSS 3 & 120 & 120 & 240 \\
& SS1 & 180 & 180 & 360 \\
& SS2 & 180 & 180 & 360 \\
& SS3 & 180 & 180 & 360 \\
& Total & 900 & 900 & 1,800 \\
\hline
\end{tabular}




\begin{tabular}{|c|c|c|c|c|}
\hline \multirow{3}{*}{ Age } & 10 or younger & 40 & 158 & 198 \\
& $11-15$ & 264 & 716 & 980 \\
& $16-20$ & 344 & 264 & 608 \\
& Above 20 yrs of age & 6 & 8 & 14 \\
& Total & 654 & 1146 & 1,800 \\
\hline \multirow{3}{*}{ Religion } & Christianity & 450 & 552 & 1002 \\
& Islam & 244 & 210 & 454 \\
& African traditional & 306 & 38 & 344 \\
\hline
\end{tabular}

\subsection{Research Instrument}

Three research instruments were used to collect data. Two of these instruments were designed by the researcher. The first instrument titled Drug Use Behaviour Inventory (DUBI), elicited information on students' knowledge, attitude and beliefs on drug use. The second instrument Drug Use Behaviour Assessment Interview Schedule (DUBAIS) sought students' opinion on drug use while the third, Life Orientation Test-Revised (LOT-R) was adapted to measure students' life orientation on drug use.

\subsection{Validation of the Instruments}

Three major approaches were adapted to validate the two instruments (Drug Use Behaviour Inventory (DUBI) and Life Orientation Test Revised (LOT-R)) using Kaiser Mayer-Olkin (KMO) and Barletts' Test of Sphericity (BTS). Data from each section of the instruments were subjected to factorial analysis starting with the original data matrices and using multiple correlations as the estimates of communalities. Correlation matrix determinant yielded 0.007, Kaiser-Mayer-Olkin (KMO) measure of sampling adequacy 0.745 while Barlelt's Test of Sphericity (BTS) yielded 119.751. These results indicated that the instruments were adequate to measure what they were designed for.

\subsection{Reliability of the Instrument}

Factorial analysis could not be done for Drug Use Behaviour Assessment interview Schedule (DUBAIS), an expert judgement was employed for validating the instrument. Panel consisting of Guidance Counsellors, Sociologists and Psychologists scrutinized all the items thoroughly. Reliability of the instruments was established through the test-retest method with an interval of three weeks on thirty (30) students. The results of the two administrations were subjected to Cronbach's alpha, Sperman Brown and Pearson Product Moment Correlation. A co-efficient of 0.775 was obtained. It was established that the two instruments (DUBI and Lot-R) correlate significantly well.

\subsection{Data Collection and Analysis}

The instruments (DUBI, LOT-R and DUBAIS) were administered personally on the subjects by the researchers throughout thirty schools in six Local Government areas after taking permission from the school authorities. Relative Significant Index (RSI), descriptive and Chi-square statistics were employed to analyse the data.

\subsubsection{Analysis and Results}

The analysis of the data indicated the following results:

Research Hypothesis:

This hypothesis stated that personal variables (age, sex, academic class and religion) do not significantly influence drug use.

To determine the influence of personal variables on drug use behaviour, scores of students on different levels of drug use behaviour (healthy and unhealthy) were cross-tabulated with their personal variables using chi-square. 
Table 2: Influence of Personal Variables on Drug Use Behaviour

\begin{tabular}{|c|c|c|c|c|c|c|}
\hline & & \multicolumn{2}{|c|}{ Different Levels of Drug Use Behaviour } & Total & \multirow[b]{2}{*}{$\mathrm{X}^{2}$} & \multirow[b]{2}{*}{$\mathbf{P}$} \\
\hline & & $\begin{array}{l}\text { Healthy behaviour } \\
\text { towards drug use }\end{array}$ & $\begin{array}{c}\text { Unhealthy behaviour towards drug } \\
\text { use }\end{array}$ & & & \\
\hline \multirow{3}{*}{ Sex } & Male & 197 & 688 & 885 & \multirow{3}{*}{11.148} & \multirow{3}{*}{.266} \\
\hline & Female & 175 & 734 & 909 & & \\
\hline & Total & 372 & 1428 & 1800 & & \\
\hline \multirow{5}{*}{ Age } & 10 yrs or younger & 49 & 149 & 198 & \multirow{5}{*}{22.282} & \multirow{5}{*}{0.008} \\
\hline & 11 to $15 \mathrm{yrs}$ & 174 & 750 & 924 & & \\
\hline & 16 to $20 \mathrm{yrs}$ & 144 & 520 & 664 & & \\
\hline & Above 20 yrs of age & 4 & 10 & 14 & & \\
\hline & Total & 374 & 1419 & 1800 & & \\
\hline \multirow{7}{*}{ Class } & JSS1 & 88 & 271 & 359 & \multirow{7}{*}{55.171} & \multirow{7}{*}{.000} \\
\hline & JSS2 & 44 & 251 & 295 & & \\
\hline & JSS3 & 16 & 83 & 99 & & \\
\hline & SS1 & 71 & 285 & 356 & & \\
\hline & SS2 & 84 & 283 & 367 & & \\
\hline & SS3 & 77 & 247 & 324 & & \\
\hline & Total & 380 & 1420 & 1800 & & \\
\hline \multirow{4}{*}{ Religion } & Christian & 197 & 891 & 1088 & \multirow{4}{*}{20.994} & \multirow{4}{*}{.050} \\
\hline & Islam & 155 & 503 & 658 & & \\
\hline & Traditional & 11 & 43 & 54 & & \\
\hline & Total & 363 & 1437 & 1800 & & \\
\hline
\end{tabular}

Table 2 shows that the chi-square value obtained for sex is $\left(X^{2}=11.148, p=0.05\right)$ and religion is $\left(X^{2}=20.994, p>0.05\right)$ at the significant levels of 0.226 and 0.05 for the two variables respectively. Since these $p$-values were equal to or greater than 0.05 values. The null hypothesis can not be rejected in the two cases. Hence, the hypothesis is accepted and it can be concluded that there is no significant influence of sex and religion on drug use behaviour.

However, for age and class, the chi-square values obtained were 22.282 and 55.171 respectively at significant levels of 0.008 for age and 0.000 for academic-class. Since, both are less than 0.05 , the null hypothesis could not be accepted. Hence, the null hypothesis was rejected in both cases and could be concluded that age and academic class level influenced drug use behaviour.

\section{Discussion of Findings}

The result of the analysis of the hypothesis shows that personal variables (sex and religion) do not significantly influence drug use behaviour was accepted while personal variables (academic- class and age) influenced drug use behaviour was rejected.

Major finding of this hypothesis was that sex has no significant influence on students' drug use behaviour. The results indicated that sex does not determine whether a respondent abuses drugs or not. In this study, females are more involved than males in drug abuse though with a slight difference. The study revealed that males are more numerous in healthy drug use habit while females involved in unhealthy, risky and addictive drug use behaviour. This finding corroborates that of Adelekan (1989) who noted that in epidemiological studies reported increasing female involvement and a trend towards polydrug use. But inconsistent with the findings of Anabel et al., (2010), they reported that males used drugs more than their female counterparts similarly, Fatoye and Morakinyo (2002) confirmed that males used alcohol, kolanut and coffee more often than females and the use of cigarettes and cannabis was exclusive preserve for males.

Furthermore, the result of this hypothesis indicates that religion has no significant influence on drug abuse. The study indicates significant relationship exist in Christian religion more than any of the two religions (Islam and Traditional). What accounted for this result is that religion variable is a vital factor that influences respondents' attitudes towards drug abuse. Religion typically includes people's beliefs about the origin of the universe, the purpose of life, supernatural forces that determine life events and it is an important predictor of personality and nature of life span. There are times when religious beliefs guide human actions. Thus the tenets of a respondent's religious affiliations may directly or indirectly influence their drug use behaviour. Both Christianity and Islam do preach against the use of alcohol and 
other hard drugs which could have influenced respondents that are devotees to have reservation for drug use. This result is consistent with that of Obot et al. ( 1993) and Odejide( 2000) on demographic predictors of drug use and consistent with the views of Gureje et al.,(2007) they reported that differences in drug use observed according to religion affiliation and Moslems were less than Christians(Cotholics and Protestants) who have used alcohol and sedatives.

Of interest is the result of the hypothesis on academic class and drug use behaviour. The result of this hypothesis on academic class was rejected. Based on the findings of this hypothesis, students from all academic classes (JSS1, 2,3 and SS1, 2, and 3) got involved in healthy, unhealthy and risky drug use behaviour categories with a least proportion of SS2, JSS2 and JSS 1 students getting involved in addictive drug use habit. What accounted for this type of drug use behaviour was that majority of students in these academic class levels have attained adolescence stage that is characterized with stress and storm of school and larger society. Additionally, it might be in realization for educational achievement that prompted majority of them to use drugs so as to read and pass during examinations. This result is similar to the findings of Obot (2000) who stressed that majority of the Nigerian students used drugs for various reasons such as to reduce stress, anxiety and to read during examinations.

Analysis of this hypothesis presents the groupings of students according to three major age brackets: 10 years or younger, 11-15 years old are in their early adolescence stage and 16-20 years old are in their late adolescence stage. The results of this study indicated a significant relationship between students' age and drug abuse, most especially for across the age category of 11-15 years who are in the early adolescence stage. The reasons for these results are many; first, early adolescent stage is characterized with habit formation. Two, students in this age category are young and the habits of young individuals are easier to change than adult people. This result is in line with the views of Odejide (2000) who explained that youths are very sensitive to advertisement and do copy things easily. Also, this result is similar to the findings of Gureje et al.,(2007),they reported that Alcohol tends to gain early prominence followed by tobacco and then cannabis.

\section{Implications for Counsell ING}

This study suggests to stakeholders in the field of education that prevention strategy should target improving academic and social - emotional learning to address risk factors for drug abuse, such as early aggression, academic failure and school dropout. Education should focus on the development of skills such as self control, emotional awareness, communication, social problem solving and academic support, especially in reading. Counselling techniques for middle and high school students should increase academic and social competencies. Some of the skills needed to be able to shun drug use habits s are; good study habits and academic supports, communication with parents and teachers, good peer relationships, self-efficacy and assertiveness, drug resistant skills, reinforcement of anti-drug attitudes, strengthening of personal commitments against drug abuse.

\section{References}

Abdulkarim, A.A; Mokuolu, O.A. \& Adeniyi, A (2005). Drug use among adolescents in Nigeria. Tropical Doctor, 35:225-228.

Abiodun, O.A., Adelekan, M. I., Ogunremi, O. O., Oni, G.A. \& Obayan A. O. I. (1994). Psychological correlates of alcohol, tobacco and cannabis use amongst secondary school students in Ilorin, Nigeria. West African Journal of Medicine, 13 (4), 213-217.

Adelekan, M.L., Makanjuola, A.B, Ndom, J.E Fayeye, J.O., Adegoke, A.A. \& Amusan, O. (2002). Monitoring trends of substance use among secondary school students in Ilorin, Nigeria. West African Journal of Medicine, 201, 28-35

Agar, M. H(1973). Ripping and Running: A Formal Ethnography of Urban Heroin Addicts. New York: Seminar Press, 1973.

Annabel, B. John, M. \& John, S. (2001)Understanding reasons for drug use amongst young people: a functional perspective. Health Education Research. (2001) 16 (4): 457-469.

Anglin, D.M., Gser, Y.I. \& Mc Glothlin, W.H. (1987). Sex differences in addict careers: Becoming Addicted. American Journal of Drug and Alcohol Use, 13,59-71.

Anochie, C., Nkanginieme, KEO,Eke, F.\& Alukor, EAD. (1999). Drug abused among secondary school students in Port Harcourt metropolis. Nigerian Journal of Medicine, 8(1), 17-23

Barnard, M. (1993). Needle sharing in context and patterns of sharing among men and women injectors and HIV risks. Addiction, $88,805-812$

Becker, J. \& Duffy, C. (2002). Women drug users and drugs service provision: Service level responses to engagement and retention: London: Home Office

Binernacki, S, (1997). Junkie Work, "Hustlers' and social status among heroin addicts. Journal of Drug Policy. Maidenhead, Berkshire: Open University press.

Bourgois, P.(1996). In search of respect selling crack in El Barrio. Cambridge: Cambridge University Press. 
Cynthia, B., Lawrence, J., D'Angelo Mark, G. \& Jocelyn, H. (2008). The changing patterns of substance abuse in urban adolescents. Retrieved from www arch pediatrics on April 25, 2008.

EL-Bassel, N.Gilbert, L. Schilling, R. \& Wada, T. (2000). Drug abuse and partner violence among women in methadone treatment Journal of Family Violence 15(3), 209-228

Eneh, A.U. \& Stanley, P.C. (2004). Pattern of substance use among secondary school students in Rivers State, Nigeria, Journal of Medicine, 13(1).

Ethen, T.A. (2000). A survey of teenage perception of parental influence of drug consumption Unpublished M.Sc dissertation, University of Wisconsin.

Ensminger, M. E. (1990). Sexual activity and problem behaviour among black urban adolescents. Child Development 61, $2032-2046$.

Ensminger, M.E., Brown, C.H. \& Kellam, S.G. (1982). Sex differences in antecedent of substance use among Adolescents. Journal of Social Issues, 38 (2), 25-42.

Fayombo, G. A. \& Aremu, S. (2000) Drug education and its effects on the educational Performance of some adolescents drug abusers in Ibadan" The Counsellor, drug abusers in Ibadan" The Counsellor, 18 (5), 378 - 387

Lasillas, Le, H., Robbin, A. S. \& Langley, R. Fatoye, F. O. \& Morakinyo, O. (2002). Substance use among secondary school students in rural and urban communities in south western Nigeria. East African Medical Journal , 79 (6), 229 - 305.

Feldman, H. (1968). Ideological supports to becoming and remaining a heroin addict. Journal of Health and Social Behaviour ,9,131139.

Finestone, H. (1957). Cates, Kicks and Color, in : Becker, H.(ed). The other side. New York: The press Sutter, A.G. (1969). Worlds of Drug abuse on the street scene: In: Cressey, D.R and Ward, D.A (eds). Delinquency, crime and Social process in New York: Harper and Row.

Flisher,A.J., Parry, C.D.H., Evans, J.M.,\& Lombard, C. (2003). Substance use by adolescents in Cape Town: Prevalence and Correlates. Journal Adolescent Health, 32, 58-65

Freund, M., Leonard, T. L., \& Lee, N. (1989). Sexual behaviour of resident street pros-titutes with their clients in Camden, New Jersey. Journal of Sex Research, 26,460-478.

Gilbert, L., E.I Bassey, N., Rajah, V. Foleno, \& Frye, V.(2001). Linking drug related activities with experiences of partner violence.A focus group study of women in methadone treatment. Violence and Victims ,16(5), 517-336.

Gorsuch, R., \& Butter, M. (1976). Initial drug abuse: A review of predisposing social psychological factors. Psychological Bulletin, 81, 120-137.

Gureje, O. Degenhardt, Olley, B. Uwakwe, R. Udofia, O. Abba, W., Olusola, A., Kipling, M.B.,\& James, C.A. (2007). A descriptive epidemiology of substance use and substance disorders in Nigeria during the early 21st century. Drug and Alcohol Dependence, 91:1-9.

Hanson, B., Beschner, G., Walters, J.M. \& Bovelle, E. (1985). Life with heroin: voices/from the inner City Lexington, Mass: Lexington Books.

Horgan, A. Cassidy, C.E. \& Corrigan, A. (1998). Child hood sexual use histories in women with drug and alcohol misuse disorders. Irish Journal of Psychological Medicine 15(3): 91-95

International Council on Alcohol and Addiction (1988). Reports and research on substance use in some urban and rural areas in Nigeria, Lausanne: International council on alcohol and addiction.

Johnson, B.D., Goldstein, P.J. Preble, E., Schmeidler, J., Lipton, D.S., Spunt, B \& Miller, T. (1985). Taking care of business. The economic of crime by heroin users. Lexington mass.

Karl, P. \& Nancy, P. (1999). Substance Use among South African University Students: a quantitative and qualitative study: Alcohol Drug abuse/Bioinformatrics/Burden of Disease: SRetrieved from Net on 5/12/2008.

Madubuike A. N. (2002). Cognitive restructuring and peer counselling techniques in the enhancement of abstinence among substance users in Lagos metropolis. Unpublished doctoral thesis, University of Ibadan.

Mc Cance-Katz, E.F., Carroll, K.M. \& Rounsaville, B.(1999). Gender differences in treatment-seeking cocaine users: Implications for treatment and prognosis. American Journal on Addiction,8, 300-311.

Murphy, S., \& Rosenbaum, M. (1995). The rhetoric of reproduction: Pregnancy and drug use. Contemporary Drug Problems, 23, 581585 .

Nwagwu, H. O., (1999). Drug addiction among Police secondary school students. Paper Presented at the Bi-annual conference of the force education officers and the first Nigerian training course for NGO's in the treatment of Drug Dependent Persons in Benin City, Nigeria, 1 - 20

Obianwu, H. (2005). Emerging serious psychopathology associated with abuse of cannabis (Indian hemp, marijuana). Tropical journal of pharmaceutical research, 4, (1), $329-330$

Obot, I. S. (2000). The Linkage between licit drugs and HIVIAIDS. Conflict and their impact on Socio-economic development in Africa. Background paper commissioned by the Drug Control Focal Point. ESCAS Department. Organisation of Africa Unity (O.A.U.). Addis Ababa Ethiopia, For Presentation to the African summit of Heads of State and Government.

Odejide, A. O. (2000). Research, prevention and treatment of alcohol and drug abuse in Nigeria: problem and prospects. Paper Presented at the $10^{\text {th }}$ Anniversary Lecture of CRISA. Jos (5 $5^{\text {th }}$ October).

Omage, E. I., \& Oshiokoya (2006) Perception of Drug Abuse Amongst Nigerian Undergraduates Published by World Journal of Medical Science

Omigbodun, O.O., \& Babalola, O. (2004). Annuals of African Medicure. Usman Danfodio University Teaching Hospital, Sokoto. 
Onigbodun, O.O. \& Babalola, O. (2004). Psychodynamics of Psychoactive substance misuse among Nigerian adolescents. Annals African Medicines 3:111-115.

Oshodi O.Y., Aina. O. F., \& Onajole. A.T (2010). Substance use among secondary school students in urban setting in Nigeria: prevalence and associated factors. African Journal of Psychiatry,13, 52-57.

Osikoya, K. A. \& Alli, A. (2006). Perception of drug abuse amongst Nigerian undergraduates. World Journal of Medical Sciences, 1 (2), 133-139.

Perkins, R. \& Bennett, G. (1985). Being a Prostitute, Boston: Allen and Unwind.

Preble, E. \& Casey, J. (1969). Taking care of business: the Heroin user's life on the streets. International Journal of Addiction, 1,1-24.

Sutter, A, (1966). The World of the Righteous Dope Fiend issues. Criminology, (2), 177-222

Sutter, A.G. (1972). Playing a Cold game: phases of a Ghetto career. Urban and culture, 1, 77-91

Sutter, A.G. (1969). Worlds of Drug abuse on the street scene: In: Cressey, D.R and Ward, D.A (eds). Delinquency, crime and Social process in New York: Harper and Row.

Shobola, A.A. (2004). The study of the effects of covert positive reinforcement and cognitive restructuring therapies on cigarette smoking behaviour of undergraduate students. Unpublished Ph.D thesis department of educational foundations and counseling, Obafemi Awolowo University, lle-lfe.

Shobola, A.A. (2009). The role of Media in Cigarette Smoking among the youths in Nigeria. In Simpson Alaba \& Esther F. Akinsola: A book for reading in Culture, Media, Technology and Psycho-social development in Nigeria 196-229.

UNODC, (2005) "World Health Organization Expert Committee on Dependence Producing Drugs. Fourteenth Report Urban Adolescent" Child Development, 61, 2032 - 2046

Waldorf, D. 1973. Careers in dope. Englewood Cliffs, NJ: Prentice-Hall. 
